RU Особенности лексических единиц

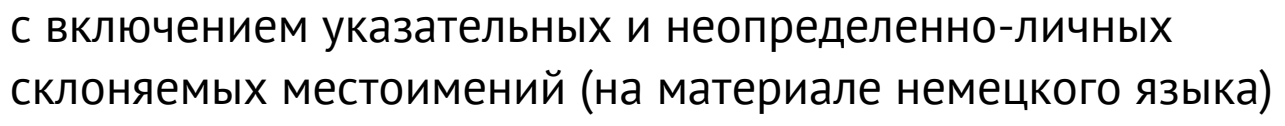

Мельгунова А. В.

Аннотация. Цель исследования - показать особенности лексических единиц немецкого языка, имеющих в своем составе склоняемые местоимения двух видов или их компоненты. В статье рассматриваются варианты функционирования в словообразовании указательных местоимений dieser «этот», jener «тот», solcher «такой», а также неопределенно-личных - jeder «каждый» и mancher «некоторый». Научная новизна заключается в комплексном рассмотрении данного вида лексических единиц с учетом их семантики и стилистической принадлежности, а также некоторых аспектов текстового функционирования. В результате охарактеризованы особенности структуры лексических единиц с компонентами данного типа, которые фигурируют в словообразовательном процессе как в усеченной, так и в полной форме, определены типичные для данной лексики словообразовательные модели и варианты стилистической принадлежности. Показаны типичные связи лексических единиц, содержащих компоненты дейктической семантики, с контекстом.

\title{
with Inclusion of Demonstrative and Indefinite-Personal Declined Pronouns (by the Material of the German Language)
}

\author{
Melgunova A. V.
}

\begin{abstract}
The aim of the research is to show the features of the lexical units of the German language which include two types of declined pronouns or their components. The article examines the options for functionning of demonstrative pronouns dieser "this", jener "that", solcher "such", as well as indefinite-personal jeder "everyone" and mancher "some", in the word formation. The scientific originality lies in a comprehensive examination of this type of lexical units, taking into account their semantics and stylistic distinctive features, as well as some aspects of textual functioning. As a result, the features of the structure of lexical units with components of this type, which appear in the word-formation process both in a reduced and full forms, are characterized; word-formation models and variants of stylistic distinctive features typi$\mathrm{cal}$ of the given vocabulary are determined. Typical connections of lexical units containing components of deictic semantics with context are shown.
\end{abstract}

\section{Введение}

Варианты функционирования местоимений в словообразовании отличаются разнообразием, которое объясняется многочисленностью типов самих местоимений и частеречной принадлежностью слов, в образовании которых они задействованы. Предметом рассмотрения являются лексические единицы немецкого языка, которые редко исследуются в контексте словообразования с местоименными компонентами - а именно включающие указательные и неопределенно-личные склоняемые местоимения или их части. Актуальность данной темы обусловлена важностью понимания роли подобной лексики в системе языка. Для достижения указанной цели необходимо решить следующие задачи: во-первых, определить степень полноты участия местоименных компонентов в соответствующих словообразовательных конструкциях; во-вторых, охарактеризовать словообразовательные модели и частеречную принадлежность изучаемых лексических единиц; в-третьих, кратко описать их стилистические черты, возможности их использования и степень связи с контекстом. В статье применяются такие методы исследования, как описательный, а также методы тематического и компонентного анализа. 
Теоретической базой исследования послужили труды российских и немецких лингвистов, посвященные морфологический системе немецкого языка - С. Т. Нефедова (2018), словообразованию - справочное издание под редакцией М. Д. Степановой (Словарь словообразовательных элементов..., 1979), монографии В. Фляйшера и И. Барц (Fleischer, Barz, 2012), Л. Айхингера (Eichinger, 2000). В работах немецких лингвистов характеризуется словообразовательная структура имен прилагательных и наречий, в том числе отмечается роль суффиксов lich (Eichinger, 2000, с. 88) и -lei (Fleischer, Barz, 2012, с. 367), типичных для рассматриваемой лексики. Отмечаемая С. Т. Нефедовым $(2018$, с. 259$)$ сема указательности как основная у местоимений dieser и јener проявляется также в словообразовании - в семантике созданных с данными компонентами лексических единиц. Кроме того, учитывались научные статьи, посвященные именно местоимениям в словообразовании как отдельной теме, в том числе на материале разных языков - Л. Г. Яцкевич (2012), А. В. Мельгунова (2019; 2021). В данных работах отмечается немногочисленность примеров лексических единиц с участием склоняемых местоимений - например, с корнями указанных местоимений - при этом структурные аналоги немецких слов могут присутствовать и в русском языке (jenseitig «потусторонний») (Мельгунова, 2021, с. 105), а в отдельных случаях лексика такого типа - в частности, в русском языке - может относиться к диалектной (например, наречие сейгод «в этом году») (Яцкевич, 2012, с. 58). При рассмотрении контекстуальных связей мы опирались на монографию М. Аверинцевой-Клиш, посвященную средствам связности текста (Averintseva-Klisch, 2013).

Практическая значимость исследования заключается в том, что его результаты могут быть использованы в преподавании лексикологии, стилистики и словообразования немецкого языка.

\section{Основная часть}

\section{Форма местоименного компонента}

Формы артикля относятся к тому же кругу форм, что и некоторые типы местоимений (Вельман, 2009, с. 126). Далее будут рассмотрены местоимения, которые по типу склонения аналогичны определенному артиклю. Все они имеют как формы мужского, среднего и женского рода, так и форму множественного числа, например, dieser «этот», dieses «это», diese «эта», diese «эти».

Таким образом, к предмету рассмотрения относятся указательные местоимения dieser «этот», jener «тот», solcher «такой», а также неопределенно-личные - jeder «каждый» и mancher «некоторый», при помощи которых создаются лексические единицы других частей речи. Количество таких слов менее тридцати.

Осталось за рамками исследования вопросительное местоимение welcher «какой», так как это единственное вопросительное местоимение с такой структурой и существуют только две лексические единицы с его участием: welcherart, welcherlei «какого бы то ни было вида». Также не учитывалось указательное местоимение, имеющее другую структуру - неизменяемое selbst «сам». Именно оно используется в словообразовании очень широко, будучи задействованным в образовании сложных существительных, прилагательных, в том числе неологизмов, имеет различные оттенки значения (Мельгунова, 2018, с. 318-319).

В связи с тем, что перечисленные выше местоимения являются изменяемыми, представляет интерес вопрос о том, в какой форме они выступают в словообразовательных конструкциях.

Здесь необходимо отметить случаи использования усеченной формы местоимения - а именно только его корня.

Это свойственно прежде всего лексическим единицам, образованным с участием местоимения dieser: во всех подобных словах (за исключением dieserart «такого рода») местоименный компонент имеет форму dies-: diesmal «в этот раз», diesjährig «этого года» и т.п. Указательное местоимение jener также выступает в усеченной форме, однако образования с ним единичны.

Остальным рассмотренным местоимениям не свойственна усеченная форма, за исключением одной лексической единицы, образованной с местоимением mancher - manchmal «иногда».

Можно упомянуть о наличии слов с компонентом -dies на втором месте, однако здесь мы имеем дело скорее не с усеченной формой, а с несклоняемым местоимением dies «это»: überdies «сверх того», ohnedies «и без того».

Промежуточную позицию между лексическими единицами с включением корня и полной формы местоимения (т.е. с окончанием) занимают слова с суффиксом -erlei: solcherlei «такого рода», jederlei «всякого рода», mancherlei «разный, всяческий».

В словообразовательном словаре данный элемент классифицирован как вариант суффикса -lei, значение которого восходит к средневерхненемецкому слову lei(e) «род, вид, способ», при этом расширенный вариант -erlei представляет собой слияние суффикса -lеi с флексией генитива (Словарь словообразовательных элементов..., 1979, с. 277). В. Фляйшер и И. Барц (Fleischer, Barz, 2012, с. 367) отмечают как типичную черту данного суффикса возможность его сочетания с местоимениями.

Формы местоимений solcher, jeder, mancher в составе других лексических единиц могут иметь окончания -en, -er, -es. Можно говорить о том, что в некоторых случаях они идентичны формам генитива для различных родов единственного или множественного числа, например, solcherweise, jedesmalig, solchenfalls, mancherorts. При словосложении (в том числе в сложнопроизводных словах) окончания согласуются с родом и числом субстантивного компонента. 


\section{Словообразовательные модели}

Среди словообразовательных моделей исследуемых лексических единиц выделяются сращение, словосложение и суффиксация.

К сращениям, то есть модели сложнопроизводных слов, можно отнести лексические единицы, включающие наряду с различными корнями еще и словообразовательные суффиксы. Иногда подвергается сомнению необходимость выделения сращения как отдельной категории (Donalies, 2011, с. 53), однако нам представляется логичным выделение данного типа словообразовательных конструкций.

Например, к сращениям относятся: прилагательное diesmalig «теперешний, нынешний», образованное на базе выражения dieses Mal «этот раз» и суффикса -ig, jenseitig «потусторонний» - от jene Seite «та сторона» и суффикса -ig и т.п. Первое из них возможно отнести также к суффиксации, если поделить его на другие составляющие: наречие diesmal и суффикс -ig.

Другим суффиксом, относящимся к средствам образования сращений на базе субстантивных словосочетаний, является -s (Словарь словообразовательных элементов..., 1979, с. 359). Он характерен для наречий, и подобные слова есть в рассмотренном материале: diesseits «по эту сторону», mancherorts «в некоторых местах».

Лексическую единицу diesbezüglich «(прил.) соответствующий, (нар.) что касается этого», по нашему мнению, тоже следует рассматривать как сращение (от dieser Bezug «это отношение» и -lich) по аналогии с другими сложнопроизводными словами с компонентом dies-. Однако можно отметить возможность другой интерпретации этой структуры, если принять во внимание существование отдельного слова bezüglich и несклоняемого варианта dies - в таком случае это словосложение.

К словосложению можно отнести примеры слов без использования словообразовательных суффиксов: diesmal «в этот раз», solchergestalt «подобным образом», jederzeit «во всяком случае».

Следует отметить переход из лексических единиц в синтаксические под влиянием экстралингвистических факторов. Например, наречие jedesmal «каждый раз» изменило написание со слитного на раздельное в связи с введением новой орфографии в 1996 году и, соответственно, перешло в разряд словосочетаний. В современном варианте немецкого языка правильным написанием считается только jedes Mal, как зафиксировано в словаре Duden (https://www.duden.de). Однако, например, слово jederzeit сохранилось в исходной форме, так как при написании раздельно его части не совпадают с существующим словосочетанием, как в предыдущем случае. Но для него, как и для большинства подобных наречий, существует и синоним в виде словосочетания с предлогом - zu jeder Zeit «в любое время».

Пример словосложения представляет собой также слово jedermann «каждый», которое, однако, является сложным местоимением, содержащим, в свою очередь, местоименный компонент, а не другой частью речи и не относится к основному предмету исследования - местоимениям в составе других частей речи. Но все же стоит кратко отметить наличие таких слов. Интересно появление в наше время также соответствующего местоимения-неологизма с аналогичной структурой jedefrau «каждая».

Новые номинации являются отражением внеязыковых данных, связанных с определенным периодом жизни людей и их менталитетом (Рацибурская, 2018, с. 54). Возникновение последнего местоимения связано с повышенным вниманием к политкорректности в отношении женщин. Существуют, однако, и сложные местоимения, которые устаревают, как произошло с архаичным на данный момент неопределенно-личным местоимением jedweder «каждый, любой», первым компонентом которого также является соответствующее указательное местоимение.

Суффиксация представлена словами с суффиксом -erlei, такими как solcherlei, которые были перечислены выше.

\section{Частеречная принадлежность}

По поводу принадлежности рассмотренных слов к частям речи можно отметить, что они в основном относятся либо к прилагательным, либо к наречиям. При этом часто на одной базе создаются слова обеих указанных частей речи: diesseits - наречие, diesseitig - прилагательное.

Прилагательные со вторым компонентом -art и суффиксом -lеі являются несклоняемыми. Например, solcherart, solcherlei «такого рода» снабжены соответствующими пометами в словаре. При использовании в качестве определения такое слово не получает окончания: solcherlei Menschen «люди такого рода» (Немецкорусский (основной) словарь, 1992, с. 776-777).

Наречия составляют половину рассмотренных лексических единиц: mancherorts «в некоторых местах, кое-где», solchenfalls «в таком случае» и др.

Если учитывать этимологию современных слов, в немецком языке есть и другие лексические единицы с устаревшими на данный момент указательными местоимениями - например, такие современные наречия, как heute «сегодня» и употребительное в южном варианте языка heuer «в этом году» образованы с включением устаревшего hiu «этот», аналогичного современному dieser.

Слово diesbezüglich может выступать и как прилагательное «соответствующий, относящийся к этому», и как наречие «что касается этого». Суффикс -lich является довольно традиционным суффиксом прилагательных. Однако ему присущ также адвербиальный характер, что обусловлено его историей, так как в Средние века компонент -liche широко использовался именно для образования наречий (Eichinger, 2000, с. 88). 
Двум наречиям с включением указательных местоимений свойственна также субстантивация - слова das Diesseits и das Jenseits служат для обозначения реального и потустороннего мира.

Слова diesseits и jenseits имеют еще одну особенность - они существуют также как предлоги, управляющие генитивом, например: jenseits der Grenze «по ту сторону границы».

Еще одним аспектом частеречной принадлежности, не относящейся к основному предмету нашего исследования, является наличие упомянутых выше сложных местоимений - как современных, так и устаревших.

С учетом устаревший лексики к словам подобного рода можно отнести также неупотребительные более союзы - dieserhalb, dieserwegen - в современном языке deshalb «поэтому», deswegen «из-за этого».

\section{Использование в контексте}

Лексике с местоименными компонентами различного типа может быть свойственно использование ее в текстах преимущественно той или иной тематики. В то время как для слов с включением личных местоимений и указательного selbst характерно употребление в текстах гуманитарной тематики (например, литературоведческой, философской и т.п.) (Мельгунова, 2019, с. 58, 60), для лексических единиц с рассмотренными в настоящей статье компонентами в основном нет привязки к определенной тематике, за исключением названных выше наречий diesseits/jenseits и случаев их субстантивации, которые часто фигурируют в философско-религиозном контексте.

Возможно, однако, отметить, что многие из рассмотренных лексических единиц относятся к определенному стилю и имеют соответствующие пометы в словарях: solcherart «такого рода»- книжный стиль, јеdesmalig «соответствующий» - канцелярский стиль, diesseitig в значении «земной»- высокий стиль.

Большинство их не используется в разговорной речи, хотя для отдельных слов - таких как наречия manchmal, diesmal - такое употребление как раз характерно.

Дейктичность, свойственная местоимениям, прежде всего указательным - так называемым истинным демонстративам, таким как dieser и т.п. (Нефедов, 2018, с. 259), влияет и на функционирование слов с подобными компонентами в контексте.

В то время как лексические единицы с включением неопределенно-личных местоимений более самостоятельны и могут быть использованы в автосемантичных предложениях - как manchmal «иногда», слова с включением указательных местоимений в большинстве случаев связаны с контекстом, как правило предшествующим.

Среди средств связности текста можно выделить грамматические и лексические средства (AverintsevaKlisch, 2013, с. 19). Наречие diesbezüglich можно отнести ко второму типу. В следующем случае, например, данное наречие дает отсылку к событиям, описанным в предыдущем предложении:

Der beliebte Party- und Skiort war im vorangegangenen Jahr zum Corona-Hotspot geworden. Diesbezüglich wurde am Freitag in Wien ein Schadenersatz-Prozess gegen den Staat Österreich verhandelt (Kaindl, 2021). / «Популярный лыжный курорт и место проведения вечеринок в прошлом году стал очагом распространения коронавирусной инфекции. В связи с этим в пятницу в Вене проходил судебный процесс о возмещении ущерба против Австрийского государства» (здесь и далее перевод автора статьи. - A. M.).

В приводимом далее примере также имеет место анафорическая отсылка. Наречие solchenfalls очень часто встречается в юридической документации, но может использоваться и в публицистике:

Müssen überdies komplette Zweige deutscher Poeterei in forensischem Eifer auf Verfehlungen im Bezug auf das weibliche Geschlecht untersucht werden? Möglicherweise würden solchenfalls Dutzende deutsche Dichter und Denker posthum mit dem „Zornigen Kaktus“ ausgezeichnet („Zorniger Kaktus“..., 2014). / «Нужно ли сверх того в судебном рвении исследовать целые области немецкой поэзии на предмет заблуждений в отношении женского пола? Возможно, в таком случае десятки немецких поэтов и мыслителей были бы посмертно награждены “Сердитым кактусом*” (т.е. *антипремией за сексизм)».

\section{Заключение}

Рассмотренный материал позволяет сделать следующие выводы. В структуре немногочисленных лексических единиц немецкого языка, образованных с участием склоняемых указательных и неопределенно-личных местоимений, имеются как сходства, так и различия. При образовании лексики такого рода используются либо усеченные местоименные компоненты, соответствующие корневым морфемам, либо их полные формы, включающие окончания.

Реализуются три словообразовательные модели - сращение, словосложение и суффиксация. Подавляющее большинство рассмотренных лексических единиц являются прилагательными, в том числе несклоняемыми, и наречиями.

Часть рассмотренных слов относится к книжному стилю и используется в языке соответствующим образом. Слова с включением корней указательных местоимений всегда отличаются связью с контекстом и указывают на различные его элементы.

Перспективой дальнейшего исследования может стать как анализ слов, образованных с участием уже устаревших местоименных компонентов, так и рассмотрение современных аспектов функционирования подобной лексики - например, в текстах юридической тематики или в официальной документации. 


\section{Источники | References}

1. Вельман Х. Грамматика немецкого языка. Звук. Слово. Предложение. Текст. М.: Московский лицей, 2009.

2. Мельгунова А. В. Местоимения как словообразовательный элемент в терминологии гуманитарных наук (на материале немецкого языка) // Филологические науки. Вопросы теории и практики. 2019. № 3. DOI: 10.30853/filnauki.2019.3.12

3. Мельгунова А. В. Словообразовательный потенциал местоимений в немецком и русском языках // Научный диалог. 2021. № 10. DOI: 10.24224/2227-1295-2021-10-101-116

4. Мельгунова А. В. Указательное местоимение selbst «сам» и его синонимы в немецком словообразовании // Филологические науки. Вопросы теории и практики. 2018. № 10 (88). DOI: 10.30853/filnauki.2018-10-2.21

5. Немецко-русский (основной) словарь: ок. 95000 слов / под ред. К. Лейна. М.: Русский язык, 1992.

6. Нефедов С. Т. Теоретическая грамматика немецкого языка. Морфология. СПб.: Изд-во Санкт-Петербургского университета, 2018.

7. Рацибурская Л. В. Социокультурные и политические аспекты современного медийного словотворчества // Социокультурные и лингвопрагматические аспекты современных словообразовательных процессов: коллективная монография / под ред. Л. В. Рацибурской. М.: ФЛИНТА, 2018.

8. Словарь словообразовательных элементов немецкого языка / под ред. М. Д. Степановой. М.: Русский язык, 1979.

9. Яцкевич Л. Г. Словообразовательный потенциал местоимений в вологодских говорах // Севернорусские говоры. 2012. № 12 .

10. Averintseva-Klisch M. Textkohärenz. Heidelberg: Universitätsverlag Winter, 2013.

11. Donalies E. Basiswissen Deutsche Wortbildung. Tübingen: UTB, 2011.

12. Eichinger L. Deutsche Wortbildung: Eine Einführung. Tübingen: Narr, 2000.

13. Fleischer W., Barz I. Wortbildung der deutschen Gegenwartssprache. Göttingen: Walter de Gruyter, 2012.

14. Kaindl F. Nur Geimpfte beim Après-Ski erlaubt? Erste Prognosen für Winterurlaub in Österreich. 2021. URL: https://www.merkur.de/reise/skiurlaub-oesterreich-2021-2022-apres-ski-corona-geimpfte-1g-regel-90991898.html

15. „Zorniger Kaktus“ für zotigen Krauß? 2014. URL: https://www.rheinpfalz.de/lokal/neustadt_artikel,-zornigerkaktus-für-zotigen-krauß-_arid,197097.html

\section{Информация об авторах | Author information}

RU Мельгунова Анна Владиславовна ${ }^{1}$, к. филол. н., доц.

${ }^{1}$ Санкт-Петербургский государственный университет

EN Melgunova Anna Vladislavovna ${ }^{1}, \mathrm{PhD}$

${ }^{1}$ St Petersburg University

${ }^{1}$ a.melgunova@spbu.ru

\section{Информация о статье | About this article}

Дата поступления рукописи (received): 12.12.2021; опубликовано (published): 31.01.2022.

Ключевые слова (keywords): словообразование немецкого языка; местоимения; словосложение; сращение; суффиксация; word formation of the German language; pronouns; compounding; fusion; suffixation. 